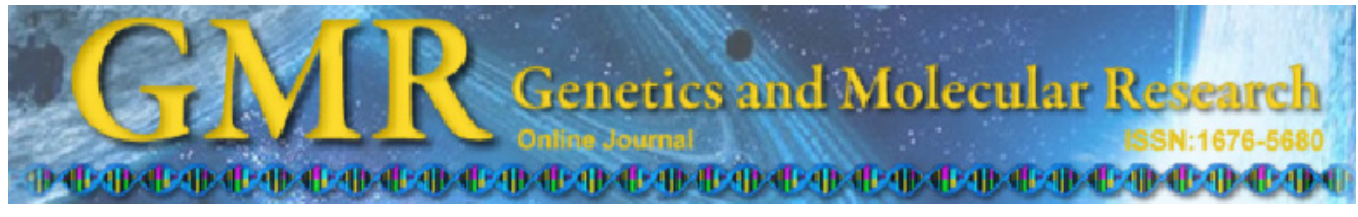

\title{
Genetic relationships of the Japanese persimmon Diospyros kaki (Ebenaceae) and related species revealed by SSR analysis
}

\author{
D.L. Guo ${ }^{1}$ and Z.R. Luo ${ }^{2}$ \\ ${ }^{1}$ College of Forestry, Henan University of Science and Technology, \\ Luoyang, China \\ ${ }^{2}$ Key Laboratory of Horticultural Plant Biology (MOE), \\ Huazhong Agricultural University, Wuhan, China \\ Corresponding author: Z.R. Luo \\ E-mail: luozhr@mail.hzau.edu.cn
}

Genet. Mol. Res. 10 (2): 1060-1068 (2011)

Received October 13, 2010

Accepted December 13, 2010

Published June 7, 2011

DOI 10.4238/vol10-2gmr1100

\begin{abstract}
Simple sequence repeat (SSR) molecular markers based on 18 primers were employed to study the genetic relationship of Japanese persimmon (Diospyros kaki) specimens. Two hundred and sixty-two bands were detected in 30 Japanese persimmon samples, including 14 Japanese and 10 Chinese genotypes of Japanese persimmon (Diospyros kaki) and six related species, D. lotus, D. glaucifolia, D. oleifera, D. rhombifolia, D. virginiana, and Jinzaoshi (unclassified - previously indicated to be $D$. kaki). All SSR primers developed from $D$. kaki were successfully employed to reveal the polymorphism in other species of Diospyros. Most of the primers were highly polymorphic, with a degree of polymorphism equal to or higher than 0.66 . The results from the neighbor-joining dendrogram and the principal coordinate analysis diagram were the same; i.e., the Chinese and Japanese genotypes and related species were separated and the relationships revealed were consistent with the known pedigrees. We also concluded that 'Xiangxitianshi' from Xiangxi municipality, Hunan Province, China, is actually a sport or somaclonal variant of 'Maekawa-Jirou', and that
\end{abstract}


'Jinzaoshi' should be classified as a distinct species of Diospyros. We found that SSR markers are a valuable tool for the estimation of genetic diversity and divergence in Diospyros.

Key words: Diospyros; Genetic relationships; SSR

\section{INTRODUCTION}

Japanese persimmon or Oriental persimmon (Diospyros kaki Thunb.) originated in Eastern Asia, in which China, Japan and Korea are the main areas of persimmon production.

Japanese persimmon can be classified into four types depending on the effect of pollination on flesh color and their patterns of astringency loss, i.e., pollination constant and non-astringent (PCNA), pollination variant and non-astringent (PVNA), pollination variant and astringent (PVA), and pollination constant and astringent (PCA).

It is well documented that the cultivation of Japanese persimmon in China can be dated back 2000 years. More than 900 varieties are known in China at present and most of them are conserved in the National Persimmon Germplasm Repository, Northwest SciTech University of Agriculture and Forestry, Yangling, Shaanxi Province. However, most of them are the PCA type. Wang (1983) reported the first Chinese origin of the PCNA type, 'Luotiantianshi', which was found in Luotian county, Hubei Province, and was confirmed by Yamada (1993). Yonemori et al. (2005) demonstrated that there were several PCNA types in Luotian county of Hubei Province in China in addition to Luotiantianshi and proposed that China should be a new origin center of PCNA germplasm besides Japan. He et al. (2000) reported that 'Jinzaoshi' persimmon was distributed in Lishui city, Zhejiang Province, and Yang et al. (1999) identified its ploidy as $2 n=2 x=30$. So far, several sorts of molecular markers such as isozymes (Tao and Sugiura, 1997), chloroplast DNA (cpDNA; Yonemori et al., 1998), random amplified polymorphic DNA (RAPD; Yamagishi et al., 2005), amplified fragment length polymorphism (AFLP; Kanzaki et al., 2000), in situ hybridization (Choi et al., 2003), inter-retrotransposon amplified polymorphism (IRAP) and retrotransposon-microsatellite amplified polymorphism (REMAP) (Guo et al., 2006; Du et al., 2009), and internal transcribed spacer (ITS; Yonemori et al., 2008) have been used for molecular characterization of Diospyros Linn.

SSR (simple sequence repeat) markers are highly polymorphic and informative, codominant, technically simple and reproducible (Gupta et al., 1996). However, SSR have not been employed in Japanese persimmon and related species. We have successfully developed a number of SSR markers in Japanese persimmon using different methods (Guo and Luo, 2004, $2006 \mathrm{~b}, 2008)$. The objective of this study was to evaluate genetic similarities and inter- and intraspecific relationships among Diospyros Linn genotypes from different origins, using these SSR markers.

\section{MATERIAL AND METHODS}

\section{Plant materials and DNA extraction}

A total of 30 Diospyros Linn genotypes were used in this study (Table 1), including 
14 Japanese, 10 Chinese genotypes of Japanese persimmon (Diospyros kaki Thunb.) and 6 related species, obtained from the Persimmon Repository, Huazhong Agricultural University, Wuhan, Hubei province, or Wuhan Botanical Garden, Chinese Academy of Science, Wuhan, Hubei Province.

Table 1. Persimmon genotypes used in this study.

\begin{tabular}{|c|c|c|c|c|c|}
\hline Number & Genotype & Species & Ploidy level & Loss type of astringency & Origin \\
\hline 1 & Fuyuu & Diospyros kaki Thunb. & $2 n=6 x=90$ & PCNA & Japan \\
\hline 2 & Matsumoto-wase & D. kaki Thunb. & $2 n=6 x=90$ & PCNA & Japan \\
\hline 3 & Uenishi-wase & D. kaki Thunb. & $2 n=6 x=90$ & PCNA & Japan \\
\hline 4 & Jirou & D. kaki Thunb. & $2 n=6 x=90$ & PCNA & Japan \\
\hline 5 & Maekawa-Jirou & D. kaki Thunb. & $2 n=6 x=90$ & PCNA & Japan \\
\hline 6 & Hana-gosho & D. kaki Thunb. & $2 n=6 x=90$ & PCNA & Japan \\
\hline 7 & Suruga & D. kaki Thunb. & $2 n=6 x=90$ & PCNA & Japan \\
\hline 8 & Oku-gosho & D. kaki Thunb. & $2 n=6 x=90$ & PCNA & Japan \\
\hline 9 & Youhou & D. kaki Thunb. & $2 n=6 x=90$ & PCNA & Japan \\
\hline 10 & Xiangxitianshi & D. kaki Thunb. & $2 n=6 x=90$ & PCNA & Japan \\
\hline 11 & Zenjimaru & D. kaki Thunb. & $2 n=6 x=90$ & PVNA & Japan \\
\hline 12 & Nishimurawase & D. kaki Thunb. & $2 n=6 x=90$ & PVNA & Japan \\
\hline 13 & Akagaki & D. kaki Thunb. & $2 n=6 x=90$ & PVNA & Japan \\
\hline 14 & Hiratanenashi & D. kaki Thunb. & $2 n=9 x=135$ & PVNA & Japan \\
\hline 15 & Male type No. 6 & D. kaki Thunb. & $2 n=6 x=90$ & - & China \\
\hline 16 & Luotiantianshi & D. kaki Thunb. & $2 n=6 x=90$ & PCNA & China \\
\hline 17 & Eshi No. 1 & D. kaki Thunb. & $2 n=6 x=90$ & PCNA & China \\
\hline 18 & Baogaitianshi & D. kaki Thunb. & $2 n=6 x=90$ & PCNA & China \\
\hline 19 & Xiaobaogaitianshi & D. kaki Thunb. & $2 n=6 x=90$ & PCNA & China \\
\hline 20 & Sifangtianshi & D. kaki Thunb. & $2 n=6 x=90$ & PCNA & China \\
\hline 21 & Xiaoguotianshi & D. kaki Thunb. & $2 n=6 x=90$ & PCNA & China \\
\hline 22 & Yunyangdongshi & D. kaki Thunb. & $2 n=6 x=90$ & PCA & China \\
\hline 23 & Mopanshi & D. kaki Thunb. & $2 n=6 x=90$ & PCA & China \\
\hline 24 & Tongpenshi & D. kaki Thunb. & $2 n=6 x=90$ & PCA & China \\
\hline 25 & Date plum & D. lotus L. & $2 n=2 x=30$ & - & China \\
\hline 26 & Chekiang persimmon & D. glaucifolia Metc. & $2 n=2 x=30$ & - & China \\
\hline 27 & Oily persimmon & D. oleifera Cheng. & $2 n=2 x=30$ & - & China \\
\hline 28 & Jinzaoshi & Diospyros spp & $2 n=2 x=30$ & - & China \\
\hline 29 & Diamond leaf persimmon & D. rhombifolia Hemsl. & $2 n=4 x=60$ & - & China \\
\hline 30 & Common persimmon & D. virginiana $\mathrm{L}$. & $2 n=4 x=60$ & - & USA \\
\hline
\end{tabular}

PCNA = pollination constant and non-astringent; PVNA = pollination variant and non-astringent; $\mathrm{PCA}=$ pollination constant and astringent.

\section{SSR analysis}

The selected primers based on previous reports (Guo and Luo, 2004, 2006b, 2008) were synthesized by Shanghai Sangon Biological Engineering Technology and Service Co. Ltd. (Table 2). SSR analysis was conducted with a polymerase chain reaction (PCR) mixture containing $30 \mathrm{ng}$ DNA, $1 \mathrm{X}$ buffer $(20 \mathrm{mM}$ Tris-HCl, $\mathrm{pH}$ 8.0, $100 \mathrm{mM} \mathrm{KCl}, 0.1 \mathrm{mM}$ EDTA, $1 \mathrm{mM}$ DTT, $0.5 \%$ Tween 20, 0.5\% Nonidet P-40, 50\% glycerol), $2.5 \mathrm{mM} \mathrm{Mg}{ }^{2+}, 0.2 \mathrm{mM}$ dNTPs, 1 U Taq DNA polymerase (TaKaRa Biotechnology Co., Ltd., Dalian, China), primer $0.3 \mu \mathrm{M}$ and water to a final volume of $20 \mu \mathrm{L}$. Amplification was carried out in an MJ Researsh Thermocycler model PTC-100. Cycling conditions were: denaturation step at $94^{\circ} \mathrm{C}$ for $4 \mathrm{~min}$ followed by 35 cycles at $94^{\circ} \mathrm{C}$ for $1 \mathrm{~min}, 50^{\circ} \mathrm{C}$ for $1 \mathrm{~min}$, and $72^{\circ} \mathrm{C}$ for $1 \mathrm{~min}$, with a final extension at $72^{\circ} \mathrm{C}$ for $10 \mathrm{~min}$.

PCR products were electrophoresed on a 3\% Metaphor agarose gel (Biowittaker, ME, USA) in 0.5X TBE buffer, stained with ethidium bromide, and photographed in a SYNGENE Automated Gel Documentation System. 


\begin{tabular}{|c|c|c|c|c|c|}
\hline $\begin{array}{l}\text { Locus name/GenBank } \\
\text { accession No. }\end{array}$ & $\begin{array}{l}\text { Repeat } \\
\text { motif }\end{array}$ & Primer sequence $\left(5^{\prime}-3^{\prime}\right)$ & $\begin{array}{l}\text { Number } \\
\text { of alleles }\end{array}$ & $\begin{array}{l}\text { Polymorphic } \\
\text { fragments }(\%)\end{array}$ & PIC \\
\hline $\begin{array}{l}\text { DKMP } 1 \\
\text { DQ204606 }\end{array}$ & $(\mathrm{GCCA})_{10}$ & $\begin{array}{l}\text { F: GGGTATCCTTGCCTGCTC } \\
\text { R: CGAACT GGT TGG TGA CGG }\end{array}$ & 16 & 75.0 & 0.56 \\
\hline $\begin{array}{l}\text { DKMP } 2 \\
\text { DO204606 }\end{array}$ & $(\mathrm{TCCG})_{5}$ & $\begin{array}{l}\text { F: GGG TAA TCT TGCCTGCTC } \\
\text { R: CTTGCTGACTCTTGGGTGT }\end{array}$ & 18 & 72.2 & 0.63 \\
\hline $\begin{array}{l}\text { DKMP } 3 \\
\text { DQ204606 }\end{array}$ & $(\mathrm{GCCA})_{5}$ & $\begin{array}{l}\text { F: ATGTGCGTTGAA AGTGTCG } \\
\text { R: GAGGGTTGTGAAATGGAA AG }\end{array}$ & 20 & 85.0 & 0.85 \\
\hline $\begin{array}{l}\text { DKMP } 4 \\
\text { DQ204605 }\end{array}$ & $(\mathrm{TA})_{5}$ & $\begin{array}{l}\text { F: TCTGCGGGTCAGTCG TCA } \\
\text { R: TTCTTTGCG GCACCACAT }\end{array}$ & 11 & 81.8 & 0.68 \\
\hline $\begin{array}{l}\text { DKMP } 5 \\
\text { DQ204609 }\end{array}$ & $(\mathrm{AG})_{6}$ & $\begin{array}{l}\text { F: CGATGGGATTACATAGGG } \\
\text { R: GCTCCGACGCATTCTTCT }\end{array}$ & 16 & 81.3 & 0.72 \\
\hline $\begin{array}{l}\text { DKMP } 7 \\
\text { DQ204618 }\end{array}$ & $(\mathrm{AG})_{15}$ & $\begin{array}{l}\text { F: CTA AATCCCCCTTTCTTCAT } \\
\text { R: TAGTCGCCTTCGTCTCCACC }\end{array}$ & 12 & 83.3 & 0.79 \\
\hline $\begin{array}{l}\text { DKMP } 8 \\
\text { DQ204618 }\end{array}$ & $(\mathrm{AG})_{7}$ & $\begin{array}{l}\text { F: AGAGAGACGACCAACGACAA } \\
\text { R: CTCACCTTTCCTGACCGCTA }\end{array}$ & 5 & 60.0 & 0.41 \\
\hline $\begin{array}{l}\text { DKMP } 11 \\
\text { DQ204619 }\end{array}$ & $(\mathrm{GT})_{5}$ & $\begin{array}{l}\text { F: CTGGAAAAAAAGACTCGG T } \\
\text { R: TGCTTGCTTCACAACCCT }\end{array}$ & 17 & 76.5 & 0.72 \\
\hline $\begin{array}{l}\text { DKMP } 12 \\
\text { DQ204620 }\end{array}$ & $(\mathrm{AC})_{5}$ & $\begin{array}{l}\text { F: ACGATTTGCGGTTACTTG } \\
\text { R: TACACCCCTGAGGAGATA }\end{array}$ & 10 & 70.0 & 0.68 \\
\hline $\begin{array}{l}\text { DKMP } 13 \\
\text { DQ222479 }\end{array}$ & $(\mathrm{CT})_{6}$ & $\begin{array}{l}\text { F: CAGTAGGTTACCGCTTAGT } \\
\text { R: ATCAGTTGAGAGGGAGAAAT }\end{array}$ & 24 & 79.1 & 0.83 \\
\hline $\begin{array}{l}\text { DKMP } 14 \\
\text { DQ222480 }\end{array}$ & $(\mathrm{GA})_{14} \ldots(\mathrm{AG})_{5} \ldots(\mathrm{GA})_{9}$ & $\begin{array}{l}\text { F: GTTACCGCATTACTCCAG } \\
\text { R: ATCTCCGACATCCAAAGC }\end{array}$ & 9 & 77.8 & 0.54 \\
\hline $\begin{array}{l}\text { DKMP } 15 \\
\text { DQ222481 }\end{array}$ & $(\mathrm{AG})_{9}$ & $\begin{array}{l}\text { F: ACGCCAGGAACATTGAAG } \\
\text { R: TTACCGCATTAGGACCAG }\end{array}$ & 23 & 78.3 & 0.62 \\
\hline $\begin{array}{l}\text { DPMP } 16 \\
\text { DQ222482 }\end{array}$ & $(\mathrm{AG})_{14}$ & $\begin{array}{l}\text { F: GCTATGACCACGATTACG } \\
\text { R: TTACCGCATTAGTCCAGT }\end{array}$ & 3 & 30.0 & 0.35 \\
\hline $\begin{array}{l}\text { DPMP } 17 \\
\text { DQ222483 }\end{array}$ & $(\mathrm{AG})_{14}$ & $\begin{array}{l}\text { F: ATTACGCCAGCATCAAGA } \\
\text { R: GCATACCGCATTAGTCCA }\end{array}$ & 22 & 77.3 & 0.74 \\
\hline $\begin{array}{l}\text { DPMP } 18 \\
\text { DQ222484 }\end{array}$ & $(\mathrm{AG})_{8}$ & $\begin{array}{l}\text { F: GCGGTTAGTTCGCACAAA } \\
\text { R: GCATTAGGACCAGTAGATTA }\end{array}$ & 16 & 68.8 & 0.61 \\
\hline $\begin{array}{l}\text { Dp1 } \\
\text { AB073009 }\end{array}$ & $(\mathrm{AG})_{5}$ & $\begin{array}{l}\text { F: ACAGCCTAAGCAGTGGTGAG } \\
\text { R: GTTGATAAGTGGGAACGCCT }\end{array}$ & 12 & 83.3 & 0.50 \\
\hline $\begin{array}{l}\text { Dp2 } \\
\text { AB073008 }\end{array}$ & $(\mathrm{GA})_{7}$ & $\begin{array}{l}\text { F: CATCTACTGCGTGCTTGTGT } \\
\text { R: TGGGAAACTCTGGATTGCTC }\end{array}$ & 13 & 75.0 & 0.86 \\
\hline $\begin{array}{l}\text { Dp6 } \\
\text { BM032607 }\end{array}$ & $(\mathrm{TGG})_{4}$ & $\begin{array}{l}\text { F: TGACGAACGGTAAACCAGTG } \\
\text { R: CAACAAGAGGAGAGACAACG }\end{array}$ & 15 & 80.0 & 0.73 \\
\hline
\end{tabular}

$\mathrm{PIC}=$ polymorphism information content.

\section{Data analysis}

Only clear, well-defined and reproducible bands were recorded, and SSR loci were scored individually. For the statistical analysis, the patterns at all SSR loci were scored as 1 for the presence of band and 0 for the absence of band in a binary data matrix for cluster analysis. Polymorphism information content (PIC) values were calculated according to Smith et al. (1997). The binary data matrix was first used to calculate the genetic distance matrix using Nei's coefficient in similarity module, which was subjected to cluster analysis using the neighbor-joining algorithm. A dendrogram was constructed with the neighbor-joining program in NTSYS-pc, version 2.1 (Rohlf, 2000). The goodness-of-fit of the clustering to the data matrix was calculated by $\mathrm{COPH}$ and MXCOMP programs. A principal coordinate analysis (PCoA) was performed based on the variance covariance matrix calculated from marker data with DCENTER and EIGEN modules and illustrated by the PROJECTIONS module.

\section{RESULTS}

Amplification was successfully done with 18 SSR markers. A total of 262 bands were 
observed, of which $74.2 \%$ were polymorphic. The total number of bands scored per primer combination ranged between 3 and 24 per primer combination, with an average of 14.5 bands per primer set. The alleles collectively yielded unique genotypes for each of the 30 Diospyros Linn genotypes, as shown in Figure 1 by the amplification profile of primer Dp2, which implied that these markers could unambiguously discriminate the 30 Diospyros Linn genotypes herein. The PIC values for the 18 primer combinations ranged from 0.35 (DPMP 16) to 0.86 (Dp2), with a mean of 0.66 (Table 2). Ten of the 18 markers were highly polymorphic, having a PIC value equal to or higher than 0.66 . The PIC results for each marker confirmed their utility to show differences between the samples analyzed in this study.

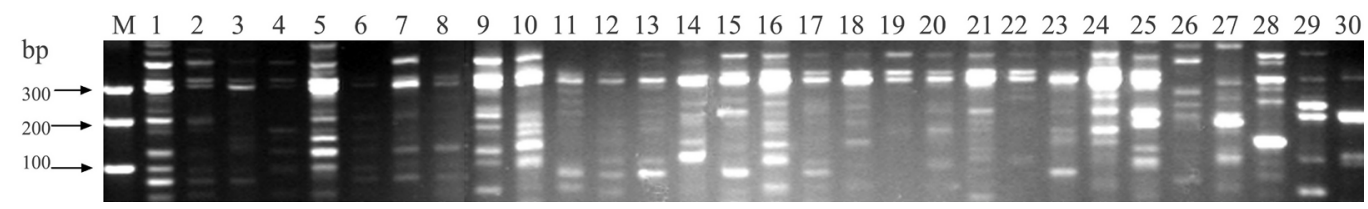

Figure 1. The SSR amplification profile of primer Dp2. M = 100-bp marker (TaKaRa, Japan). The genotype numbers were the same as those in Table 1.

The neighbor-joining dendrogram based on the genetic distance matrix is shown in Figure 2. The correlation between the genetic distance matrix and the cophenetic matrix derived from the tree produced by neighbor-joining was 0.853 , corresponding to a good fitness. It is noted that in the dendrogram the genotypes could be grouped in line with their morphological characteristics and their geographical origin.

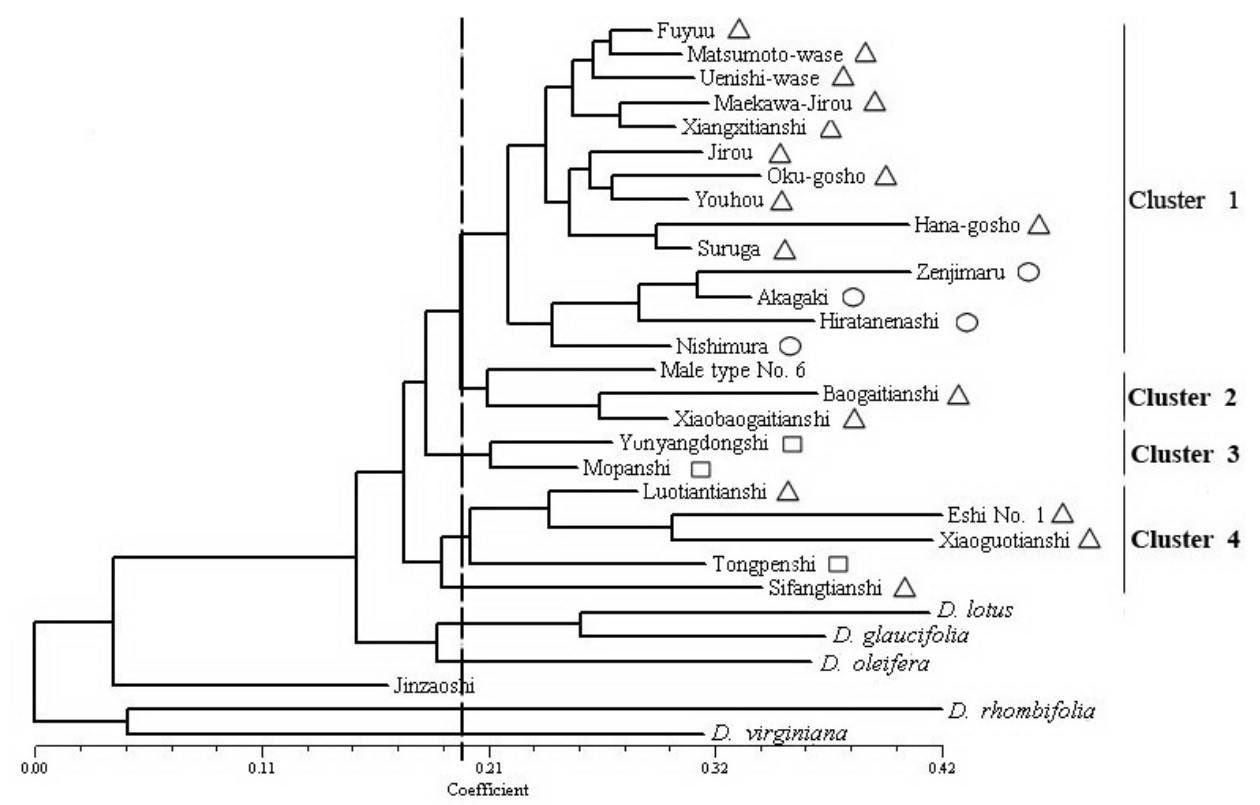

Figure 2. Neighbor-joining dendrogram of 30 Japanese persimmon genotypes based on proportion of shared allele distance from the SSR data. Triangles = PCNA-type Japanese persimmon; circles = PVNA-type Japanese persimmon; squares $=$ PCA-type Japanese persimmon. See Table 1 for abbreviations. 
Several major clusters can be identified at the similarity level of 0.196 . The related and domesticated ones formed distinct groups in the dendrogram. Cluster 1 included all Japanese genotypes, which could be subdivided into two subgroups. The Japanese PCNA genotypes grouped together including 'Fuyuu', 'Matsumoto-wase', 'Uenishi-wase', 'Jirou', 'MaekawaJirou', 'Hana-gosho', 'Youhou', 'Oku-gosho', and 'Suruga'. 'Nishimura-wase', a PVNA type, and 'Xiangxitianshi' also clustered in this subgroup. Another subgroup was composed of 'Zenjimaru', 'Akagaki' and 'Hiratanenashi', which are all PVNA types. Among these genotypes, 'Uenishi-wase' and 'Matsumoto-wase', bud sports of 'Matsumoto-wase' and 'Fuyuu', respectively (Yonemori et al., 2000) were well differentiated in the dendrogram. Cluster 2 comprised 'Male type No. 6', 'Baogaitianshi' and 'Xiaobaogaitianshi'. 'Yunyangdongshi' (PCA) and 'Mopanshi' (PCA) gathered in the Cluster 3, and Cluster 4 included 'Luotiantianshi', 'Eshi No. 1', 'Xiaoguotianshi', and 'Tongpenshi'. 'Sifangtianshi' formed one branch individually. The genotypes in these three groups are mainly of Chinese ones, while PCNA and PCA types were not distinctly separated. These three subgroups were scattered as a whole. The related species look like a polyphyletic grouping with 5 branches. D. lotus and D. glandulosa formed one branch; the other related species clustered together. Overall, the dendrogram indicated a clear genetic divergence between Japanese and Chinese genotypes.

Principal coordinate analysis was performed to better understand the genetic relationships. Figure 3 displays the distribution of different genotypes according to the two principal axes of variation using PCoA, which revealed classifications similar to the cluster analysis. In this analysis, the first and the second coordinates explained 16.9 and $10.3 \%$ of the variation, respectively. The first three eigen vectors accounted for $36.3 \%$ of the variation observed.

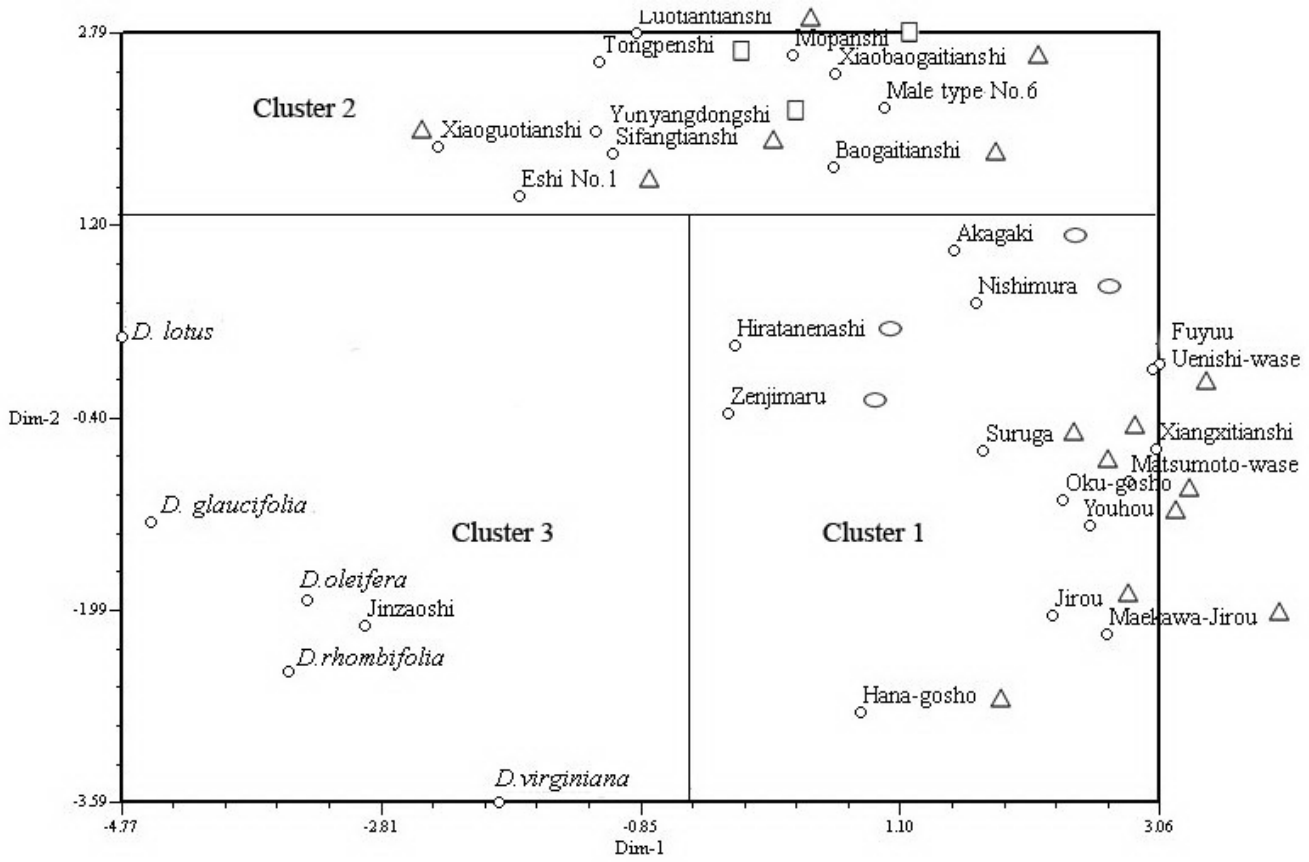

Figure 3. Diagram showing the relationships among 30 genotypes based on principal coordinate analysis using SSR. 


\section{DISCUSSION}

The detection of polymorphisms of the SSRs via agarose gel system is less expensive and more widely available. Kohli et al. (2004) reported that a high-resolution agarose gel and $6 \%$ denaturing PAGE were comparable for the differentiation of the STMS alleles in rice (Senior and Heun, 1993). Senior et al. (1998) showed that the patterns of genetic divergence revealed by the SSR polymorphisms on agarose gel were consistent with known pedigrees in maize. Because persimmon is hexaploid, multiple amplification products can be obtained from a single locus. In such case, it should be quite difficult to distinguish an allelic band from a shadow band on an acrylamide gel. Therefore, we also employed an agarose gel system in SSR analysis and obtained reliable results.

All SSR primers developed from $D$. kaki Thunb. used in this study were successfully employed to reveal the polymorphism in other species of Diospyros Linn. Most of the primers gave rise to more than 10 alleles. It is comparable with Naval et al. (2010). The alleles detected in the other species (Senior et al., 1998; Kohli et al., 2004) were fewer than in D. kaki Thunb. due to the larger chromosome numbers and high ploidy levels of this genus.

The neighbor-joining dendrogram and the PCoA diagram yielded similar structures, i.e., they revealed that, as shown in Figures 2 and 3, the Japanese varieties (Cluster 1), the Chinese genotypes (Cluster 2) and the related species (Cluster 3) were distinctly differentiated, suggesting they have a different genetic background. The results of Naval et al. (2010) also showed a unique clade of PCNA Japanese cultivars, suggesting an independent evolution. The Japanese genotypes, which have the bud sport relationship, were exactly identified. The fact that cluster results finely matched with the known relationships of Japanese genotypes in the dendrogram indicated that the discriminating ability of SSR analysis was good and that the results were very reliable. SSR genotype is usually the same in wild type and mutant. This study revealed the different SSR patterns between the original varieties and sports as in grape (Crespan, 2004; Ibáñez et al., 2009). Maybe some changes occurred in these three genotypes after a long cultivation, domestication, and intercrossing history. The results of Guo and Luo (2006a) also revealed the distinct difference between 'Fuyuu', 'Matsumoto-wase' and 'Uenishi-wase' by SRAP markers. They maybe had exceeded the original relationships and formed distinct genotypes. This needs to be verified by more research. Because the main objective of this study was to analyze the Chinese genotypes and the relationships between Japanese genotypes were very clear, only Japanese PCNA and PVNA cultivars as Japanese-type cultivars were used; no PCA type was included. However, these types do not exist in China. If Japanese PCA cultivars were also analyzed, there might have been more overlap of Chinese and Japanese cultivars in the phylogenetic tree. It needs to be further explored in the future.

'Xiangxitianshi' from Xiangxi municipality, Hunan Province, China, always clustered with 'Maekawa-Jirou', a Japanese genotype, and in the Japanese groups in the dendrogram and unrooted tree (Cluster 1 or Group 1). Such close relationship between them may suggest that 'Xiangxitianshi' is related to Japanese genotypes and may actually be a sport or somaclonal variant of 'Maekawa-Jirou', in agreement with our previous study (Guo et al., 2006).

Choi et al. (2003) showed that D. kaki was close to three diploids, D. glandulosa, D. oleifera and D. lotus. Nakamura and Kobayashi (1994) and Yonemori et al. (1998) showed that $D$. rhombifolia was the most distant species. These contentions were all supported by the results of the present analysis. D. oleifera, D. lotus and D. glaucifolia are closer to D. kaki than 
D. rhombifolia and D. virginiana, as shown in the dendrogram and the unrooted tree.

'Jinzaoshi' has only been described in China. It is distinct from other Diospyros species by neighbor-joining. It was clustered with the Japanese persimmon-related species in the neighbor-joining dendrogram and PCoA diagram. The relationship of 'Jinzaoshi' with the rest of the genotypes is more clearly depicted in the PCoA diagram, which demonstrated that it may be a distinct species or a unique genotype at least and could be included in Diospyros, in line with our previous study (Guo and Luo, 2006a). This hypothesis should be confirmed by more evidence in the future.

There are many astringent and PVNA cultivars throughout Japan. In contrast, PCNAtype persimmon is limited to the central part of Japan (Yamada, 1993), where only six cultivars were recorded after eliminating the synonyms. At present, only 18 PCNA genotypes of Japanese origin are conserved at Akitsu, Japan (Yamada, 2005). Yonemori et al. (2005) confirmed the existence of some PCNA persimmon apart from 'Luotiantianshi'. In China, the PCNA types are limited to the Dabieshan region of Hubei Province, while the PCA types are widely spread and where no PVNA and PVA types are found at present. The main breeding objective of Japanese persimmon is to develop new cultivars that are commercially acceptable PCNA. Most PCNA cultivars are of Japanese origin and have a narrow genetic diversity, and the natural loss of astringency in the PCNA type is a trait that is qualitatively inherited (Yonemori et al., 2000). However, Ikegami et al. (2004) reported that the mechanism of PCNA in 'Luotiantianshi' was quite different from that of Japanese PCNA cultivars due to different modes of evolution between the Chinese and Japanese PCNA types. Therefore, the Japanese persimmon germplasm in China provides a largely unexplored gene pool with great potential for broadening the genetic base of world persimmon breeding. We successfully isolated SSR markers from the genome of Diospyros Linn and studied the genetic relationships of some Japanese persimmon genotypes from China and Japan and related species. The SSR markers provide new tools for the breeding and selection of novel cultivars and studies of the genetic diversity of Japanese persimmon. However, it remains to be determined how difference in genetic background between the Chinese and the Japanese PCNA types correlates with the history of their cultivars. More studies are needed to further this research in the future.

\section{ACKNOWLEDGMENTS}

The authors are grateful to Dr. Jihong Liu, Huazhong Agricultural University, for reading the manuscript. Research supported by the Natural Science Foundation of China (NSFC \#30921002 and \#30871686).

\section{REFERENCES}

Choi YA, Tao R, Yonemori K and Sugiura A (2003). Genomic distribution of three repetitive DNAs in cultivated hexaploid Diospyros spp. (D. kaki and D. virginiana) and their wild relatives. Genes Genet. Syst. 78: 301-308.

Crespan M (2004). Evidence on the evolution of polymorphism of microsatellite markers in varieties of Vitis vinifera $\mathrm{L}$. Theor. Appl. Genet. 108: 231-237.

Du XY, Zhang QL and Luo ZR (2009). Development of retrotransposon primers and their utilization for germplasm identification in Diospyros spp. (Ebenaceae). Tree Genet. Genom. 5: 235-245.

Guo DL and Luo ZR (2004). Establishment of SSR technique of Diospyros kaki and D. lotus. J. Agri. Biotechnol. 12: 386-389.

Guo DL and Luo ZR (2006a). Genetic relationships of some PCNA persimmons (Diospyros kaki Thunb.) from China and 
Japan revealed by SRAP analysis. Genet. Res. Crop Evol. 53: 1597-1603.

Guo DL and Luo ZR (2006b). Development of SSR primers using ISSR-PCR in Diospyros kaki Thunb. Mol. Ecol. Notes 6: 621-622.

Guo DL and Luo ZR (2008). Microsatellite isolation and characterization in Japanese persimmon (Diospyros kaki). Biochem. Genet. 46: 323-328.

Guo DL, Zhang HQ and Luo ZR (2006). Genetic relationships of Diospyros kaki Thunb. and related species revealed by IRAP and REMAP analysis. Plant Sci. 170: 528-533.

Gupta PK, Balyan HS, Sharma PC and Ramesh B (1996). Microsatellites in plants: a new class of molecular markers. Curr. Sci. 70: 45-54.

He XY, He L and Xie JQ (2000). Development of “Jinzaoshi” persimmon industry. Q. Forest By-product Special. China 2: $47-48$

Ibáñez J, Velez MD, de Andres MT and Borrego J (2009). Molecular markers for establishing distinctness in vegetatively propagated crops: a case study in grapevine. Theor. Appl. Genet. 119: 1213-1222.

Ikegami A, Yonemori K, Sugiura A, Sato A, et al. (2004). Segregation of astringency in F1 progenies derived from crosses between pollination constant, non-astringent (PCNA) persimmon cultivars. HortScience 39: 371-374.

Kanzaki S, Yonemori K, Sugiura A, Sato A, et al. (2000). Analysis of the genetic relationships among pollination-constant and non-astringent (PCNA) cultivars of persimmon (Diospyros kaki Thunb.) from Japan and China using amplified fragment length polymorphism (AFLP). J. Jpn. Soc. Hort. Sci. 69: 665-670.

Kohli S, Mohapatra T, Das SR, Singh AK, et al. (2004). Composite genetic structure of rice land races revealed by STMS markers. Curr. Sci. 86: 850-854.

Nakamura Y and Kobayashi S (1994). DNA restriction fragment length variability in Diospyros kaki and related Diospyros species. HortScience 29: 809-811.

Naval M, Zuriaga E, Pecchioli S, Llácer G, et al. (2010). Analysis of genetic diversity among persimmon cultivars using microsatellite markers. Tree Genet. Genom. 6: 677-687.

Rohlf FJ (2000). NTSYS-pc: Numerical Taxonomy and Multivariate Analysis System. Version 2.1. Exeter Publications, New York.

Senior ML and Heun M (1993). Mapping maize microsatellites and polymerase chain reaction confirmation of the targeted repeats using a CT primer. Genome 36: 884-889.

Senior ML, Murphy JP, Goodman MM and Stuber CW (1998). Utility of SSRs for determining genetic similarities and relationships in maize using an agarose gel system. Crop Sci. 38: 1088-1098.

Smith JSC, Chin ECL, Shu H, Smith OS, et al. (1997). An evaluation of the utility of SSR loci as molecular markers in maize (Zea mays L.): comparisons with data from RFLPs and pedigree. Theor. Appl. Genet. 95: 163-173.

Tao R and Sugiura A (1997). Cultivar identification of Japanese persimmon by leaf isozymes. Hort. Sci. 22: 932-935.

Wang RZ (1983). The discussion about the origin of Luotiantianshi persimmon. China Fruits 2: 16-19.

Yamada M (1993). Persimmon breeding in Japan. Jpn. Agric. Res. Q. 27: 33-37.

Yamada M (2005). Persimmon genetics resources and breeding in Japan. Acta. Hort. 685: 51-6 4.

Yamagishi M, Matsumoto S, Nakatsuka A and Itamura H (2005). Identification of persimmon (Diospyros kaki) cultivars and phenetic relationships between Diospyros species by more effective RAPD analysis. Sci. Hortic. 105: 283-290.

Yang Y, Wang RZ and Li GC (1999). Study on chromosome numbers of Diospyros and their varieties. Acta. Agric. Boreali-occidentalis. Sin. 8: 64-67.

Yonemori K, Kanzaki S, Parfitt DE, Utsunomiya N, et al. (1998). Phylogenetic relationship of Diospyros kaki (persimmon) to Diospyros spp. (Ebenaceae) of Thailand and four temperate zone Diospyros spp. from an analysis of RFLP variation in amplified cpDNA. Genome 41: 173-182.

Yonemori K, Sugiura A and Yamada M (2000). Persimmon genetics and breeding. Plant Breed. Rev. 19: 191-225.

Yonemori K, Ikegami A, Kitajima A, Sato A, et al. (2005). Existence of several pollination constant non-astringent type persimmons in China. Acta Hort. 685: 77-83.

Yonemori K, Honsho C, Kanzaki S, Ino H, et al. (2008). Sequence analyses of the ITS regions and the matK gene for determining phylogenetic relationships of Diospyros kaki (persimmon) with other Diospyros (Ebenaceae) species. Tree Genet. Genom. 4: 149-158. 